\title{
The human Ec peptide: the active core of a progression growth factor with species-specific mode of action
}

\author{
Efstathia Papageorgiou, * Anastassios Philippou,* Athanasios Armakolas, * \\ Panagiotis F. Christopoulos, Andreas Dimakakos, Michael Koutsilieris
}

Department of Experimental Physiology, Medical School, National and Kapodistrian University of Athens, Athens, Greece

*Equal contribution to this manuscript

\begin{abstract}
OBJECTIVE: Preferential IGF-1Ec expression has been firmly associated with skeletal muscle repair mechanisms, post-infarction remodeling of the myocardium, the pathophysiology of endometriosis and prostate cancer biology. Therefore, we have studied the possible biological significance of synthetic Ec peptide, a putative cleavage product of IGF-1Ec in PC-3 cells and C2C12 myoblasts. DESIGN: We had previously designed and synthesized commercially peptides corresponding to the human Ec and its mouse igfl counterpart as well as synthetic peptides that correspond to parts of the hEc. Using proliferation and mitogenic signaling assays, we tested their effect on PC-3 cells and $\mathrm{C} 2 \mathrm{C} 12$ myoblasts at different doses and in different culture conditions. RESULTS: Human Ec, hEc, was documented as exerting progression but not competence growth factor actions, activating ERK1/2 without affecting Akt phosphorylation in PC-3 cells. A narrow concentration range of hEc (5-50nM) stimulated the growth of PC-3 cells grown in culture media supplemented with $10 \%$ FBS. hEc did not stimulate the growth of PC-3 cells cultured with media containing $0.5 \%$ FBS or in mouse $\mathrm{C} 2 \mathrm{C} 12$ myoblasts under any culture conditions. The activity of hEc was blocked by a neutralizing anti-human IGF-1Ec antibody but not by a neutralizing anti-human IGF-1 receptor antibody. The synthetic mouse Ec was inactive in human PC-3 cells; however, it stimulated significantly the proliferation of mouse C2C12. By analyzing the bioactivity of synthetic hEc fragments, we documented that hEc's active core is located in the last 4aa of its C-terminal end. CONCLUSION: The hEc peptide is an important progression factor for human $\mathrm{PC}-3$ prostate cancer cells.
\end{abstract}

Key words: Active core, C2C12 myoblasts, Ec peptide, IGF-1Ec, PC-3 cells

Address for correspondence:

Michael Koutsilieris, MD, PhD, Professor \& Chairman, Department of Experimental Physiology, Medical School, National \& Kapodistrian University of Athens, 75 Mikras Asias Street, 11527, Goudi-Athens, Greece; Tel.: +30 2107462507 ; Fax: +30 210 7462571; E-mail: mkoutsil@med.uoa.gr Received: 07-04-2016, Accepted: 15-07-2016

\section{INTRODUCTION}

Insulin-like growth factor 1 (IGF-1) is a key intercessor in human physiology and pathophysiology, including cancer. ${ }^{1}$ Type I IGF-1 receptor (IGF-1R) mediates the effects of IGF-1 by triggering two major intracellular signaling cascades: the phosphatidylino- 
sitol 3-kinase/AKT kinase (PI3K/AKT) pathway and the Raf kinase/mitogen activated protein kinase (Raf/MAPK) pathway. ${ }^{2,3}$ IGF-1R-dependent signaling regulates a wide range of cellular responses, including cell proliferation. IGF-1 can act both as a competence growth factor, stimulating the "G0 to G1 transition" of quiescent/dormant cells, and as a progression growth factor, stimulating the "G1 to G2 transition" of somatic cells in the cell cycle., ${ }^{4,5}$

By alternative splicing of exons 5 and 6, human igfl produces three transcripts, namely IGF-1Ea, IGF-1Eb and IGF-1Ec. ${ }^{3}$ Since they contain exon 3 and exon 4 , all of them can produce mature IGF-1. However, translation of these transcripts produces different E-domain peptides, namely Ea, Eb, and Ec. It is, therefore conceivable that the preferential expression of IGF-1Ec detected in several experimental settings after tissue damage supports the need of the injured tissue for an auxiliary to IGF-1, Ec-related bioactivity. ${ }^{6-9}$ Indeed, several studies have confirmed that synthetic human $\mathrm{Ec}(\mathrm{hEc})$ and mouse $\mathrm{E}(\mathrm{mE})$ peptide [a product of the $\mathrm{E}$ domain of IGF-1Eb transcript of mouse $i g f 1]$ possess mitogenic, angiogenic and migratory growth factor activity in vitro. In addition, other studies in several experimental settings, including prostate cancer models, in vitro and in vivo, ${ }^{6,8,19}$ have suggested that Ec may act via an IGF-1R-independent signaling pathway. ${ }^{6,15-17}$ Moreover, using molecular engineering, we have recently produced human PC-3 prostate cancer transfectans with specific Ec overexpression (PC-3hEc cells). These PC-3hEc cells have been documented, using in vitro and in vivo models, ${ }^{20}$ as possessing an increased oncogenic capacity and invasive/metastatic capability.

However, the biologic importance of synthetic $\mathrm{E}$ domain-related peptides has been challenged in studies using various bioassay systems, including mesenchymal stem cells and mouse C2C12 myoblasts. ${ }^{21}$ Since there exist significant amino acid (aa) differences (Table 1) between $\mathrm{hEc}$ and its mouse counterpart $\mathrm{mE}$ (putative product of the IGF-1Eb of mouse igfl), we have analyzed possible differences in the mode of action of synthetic $\mathrm{hEc}$ and $\mathrm{mE}$, employing various experimental models (human PC-3 prostate cancer cells and mouse $\mathrm{C} 2 \mathrm{C} 12$ myoblasts) and various cell culture conditions. $^{22}$
Table 1. The amino acid (aa) sequence of synthetic human (hEc) and mouse $(\mathrm{mE})$ peptides* tested for bioactivity, in vitro

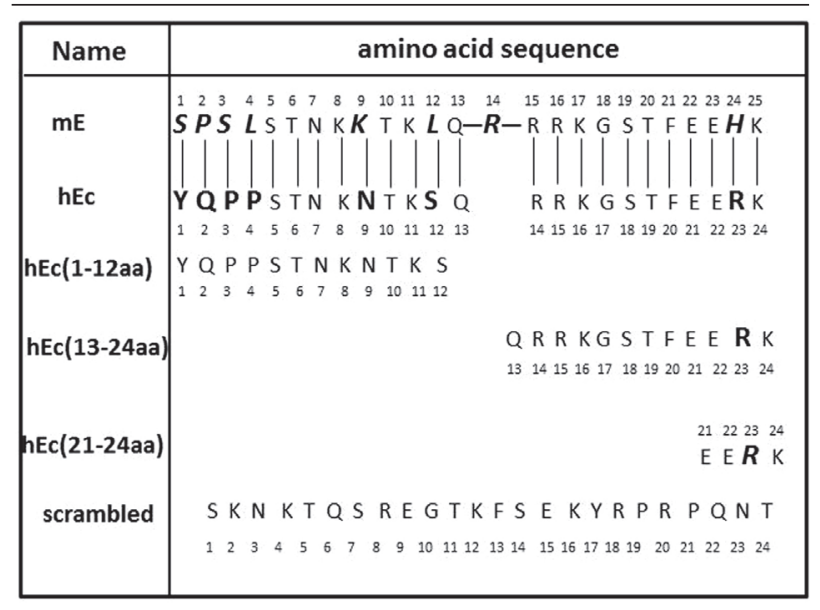

* Note the remarkable differences between $\mathrm{hEc}$ and $\mathrm{mE}$ peptides

Herein we report that $h E c$ peptide [24 amino acids of the carboxy (C)-terminal end of human Ec], is a significant progression factor but not a competence growth factor, stimulating the growth of human PC-3 cells grown in culture media supplemented with $10 \%$ fetal bovine serum (10\% FBS). Notably, hEc did not stimulate significantly the growth of mouse $\mathrm{C} 2 \mathrm{C} 12$ myoblasts under any experimental condition. In addition, $\mathrm{mE}$ stimulated the growth of mouse $\mathrm{C} 2 \mathrm{C} 12$ myoblasts but not that of human PC-3 cells under any experimental condition. Moreover, hEc and all of the synthetic fragments that contained the last 4 amino acids of hEc's C-terminal end activated ERK1/2 without affecting AKT phosphorylation in human PC-3 prostate cancer cells.

\section{MATERIALS AND METHODS}

\section{Synthetic peptides}

We had previously designed and synthesized commercially peptides corresponding to human Ec (last 24 amino acids of human Ec) and to its mouse igfl counterpart, a putative product of the IGF-1Eb transcript (last 25 amino acids of the mouse $\mathrm{Eb} ; \mathrm{mE}$ ), as well as various synthetic peptides that correspond to parts of the $\mathrm{hEc}$, namely hEc (1-12; N-terminal end), hEc (13-24; C-terminal end) and hEc (21-24; C-terminal end) (Table 1). Furthermore, we synthesized a scrambled peptide, which was designed to contain the same amino acids of $\mathrm{hEc}$, in a random 
manner, avoiding any aa sequence that corresponds to hEc or $\mathrm{mE}$ (Table 1). The scrambled peptide was used as negative control. In addition, the commercially available mature IGF-1 (rhIGF-1, Chemicon International Inc., Temecula, CA, USA) was used as positive control in our bioassays systems.

\section{Cell Cultures}

Human PC-3 prostate cancer cells (PC-3 cells) and mouse $\mathrm{C} 2 \mathrm{C} 12$ myoblasts were obtained from the American Type Culture Collection (ATCC, Manassas, VA, USA) and cultured in Dulbecco's Modified Eagle's Medium (DMEM) (Gibco, Invitrogen, Carlsbad, CA), supplemented with $10 \%$ fetal bovine serum (FBS) (Gibco, Invitrogen), containing $100 \mathrm{U} /$ $\mathrm{mL}$ penicillin/streptomycin (Gibco, Invitrogen). The cells were grown at $37^{\circ} \mathrm{C}$ in a humidified atmosphere of $5 \% \mathrm{CO}_{2}$. The cells were initially cultured to reach $70-80 \%$ confluence. Following this, two types of experiments were performed to search for evidence as to whether the synthetic peptides under investigation are either competence or progression growth factors. In the first series of experiments, the cells were seeded for $24 \mathrm{hrs}$ after plating and the media continued to be supplemented with $10 \%$ FBS during the experimental procedure. We then added various doses of the scrambled peptide (negative control), mature IGF-1 peptide (positive control), hEc, $\mathrm{mE}$ and the synthetic hEc fragments, hEc (1-12), hEc (13-24), hEc, ${ }^{21-24}$ for $48 \mathrm{hrs}$. In the second type of experiments, after the cell plating, the culture media were changed to contain $0.5 \%$ FBS for $48 \mathrm{hrs}$. The latter is known to increase the distribution of cells into the G0 phase, thus facilitating the testing of putative competence growth factor activity in vitro. A competence growth factor "pushes" cells to enter the cell cycle/G0-G1 transition. ${ }^{4,5}$ In both series of experiments, human PC-3 cells and mouse $\mathrm{C} 2 \mathrm{C} 12$ myoblasts were challenged with various concentrations of synthetic peptides for $48 \mathrm{hrs}(0.5 \mathrm{nM}$ up to 200nM; final concentration/well).

\section{Cell proliferation assays}

(a) The rate of proliferation/metabolism of cells was measured using the 3-(4,5-dimethylthiazol-2-yl)-2.5 diphenyl tetrazolium bromide (MTT assays; Sigma Ltd). Cells were plated in 96-well plates at a cell density of $10^{3}$ cells/well and grown in media $(150 \mu 1 /$ well $)$ supplemented with either $10 \%$ or $0.5 \%$ FBS, depending on the experiment. After treatment with synthetic peptides, $15 \mu$ of $(5 \mathrm{mg} / \mathrm{ml})$ MTT was added to each well in a humidified atmosphere $\left(37^{\circ} \mathrm{C}, 5 \% \mathrm{CO}_{2}\right)$ for up to $4 \mathrm{hr}$. Then MTT was aspirated and $150 \mathrm{ml}$ of DMSO was added to each well. The optical density (OD) was measured at $450 \mathrm{~nm}$ using a microplate reader (VersaMax; Molecular Devices, Sunnyvale, CA, USA), as described previously. ${ }^{23}$

(b) The actual number of alive PC-3 and $\mathrm{C} 2 \mathrm{C} 12$ cells in cultures was assessed using the trypan blue exclusion assays, whereby cells were plated (at a cell density of $8 \times 10^{4}$ cells/well) in 12-well plates and exposed to various doses of the synthetic peptides under investigation. After $48 \mathrm{hrs}$, the cells were harvested and counted by the trypan blue exclusion method, as described previously. ${ }^{23}$

(c) The DNA content from identical experiments was extracted by the phenol/chloroform method. The DNA content was measured using a spectrophotometer (Biospec Nano; Shimadzu Scientific Instruments, Columbia, MD, USA). This analysis provided evidence for the rate of DNA synthesis in vitro. ${ }^{24}$

\section{Characterization of $h E c \& \boldsymbol{m} E$ activity}

In order to investigate whether IGF-1R mediates the activity of synthetic hEc in the PC-3 cells, the cell cultures were pre-incubated for $1 \mathrm{hr}$ with either a monoclonal anti-human IGF-1R neutralizing antibody (R\&D Systems; Minneapolis, MN, USA) or a polyclonal rabbit anti-human IGF-1Ec antibody. The latter was raised against the 24 amino acids of the $\mathrm{hEc} .^{22}$ The IGF-1R neutralizing antibody was used at a concentration of $10 \mu \mathrm{g} / \mathrm{ml}$ (1:50 dilution), following the manufacturer's recommendation, and the rabbit anti-IGF-1Ec antibody was used at 1:50 dilution, as previously described. ${ }^{20}$

\section{Cell cycle analysis by flow cytometry}

Cells were seeded in 12-well plates at a cell density of $8 \times 10^{4}$ cells/well and then challenged by synthetic peptides, as described above. After the experimental procedure, adherent and floating cells were combined, washed with PBS and fixed overnight at $4^{\circ} \mathrm{C}$ in $70 \%$ ethanol in PBS. Fixed cells were then stained with CyStain DNA 1step (Partec GmbH; Münster, Germany). Cell cycle analysis was performed using a 
FACS Calibur CyFlow ML Partec flow cytometer, using the ModFit and Flowmax 3.0 software. This analysis provided evidence for the effects of the synthetic peptides under investigation in the distribution of PC-3 cells into the various phases of the cell cycle (G0/G1, S and G2/M phases), as described previously. ${ }^{15,20,23,24}$

\section{Western analysis}

Cells were seeded in 6-well plates grown in culture media supplemented with $10 \%$ FBS and challenged with synthetic peptides under investigation for 5 , 15 and $30 \mathrm{~min}$. Cells were extracted using RIPA buffer (Cell Signaling; Beverly, MA, USA) supplemented with protease and phosphatase inhibitors (Cell Signaling; Beverly, MA, USA). After $30 \mathrm{~min}$ of incubation on ice, the cell lysates were cleared by centrifugation $\left(14,000 \mathrm{rpm}\right.$, for $30 \mathrm{~min}$ at $\left.4^{\circ} \mathrm{C}\right)$. Protein concentration was measured using the BCA Protein Assay Kit (Pierce Biotechnology; Rockford, IL, USA). An equal amount of protein extracts (20 $\mu \mathrm{g})$ was heated at $95^{\circ} \mathrm{C}$ for $5 \mathrm{~min}$, electrophoresed in $12 \%$ SDS-PAGE under denaturing conditions and transferred onto a PVDF membrane (BIO-RAD Laboratories; Hercules, CA, USA). The blots were blocked with TBS-T (20 mmol/L Tris-HCl, pH 7.6, $137 \mathrm{mmol} / \mathrm{L} \mathrm{NaCl}$, and $0.1 \%$ Tween 20 ) containing $5 \%$ nonfat dried milk at room temperature for $1 \mathrm{hr}$. The membranes were probed overnight with primary antibodies against phospho-ERK1/2 and phospho-AKT (Cell Signaling; Beverly, MA, USA) at 1:1,000 dilution in TBS/T containing 5\% BSA (Santa Cruz Biotechnology; Santa Cruz, CA, USA), and with GAPDH (1:2,000 dilution; Santa Cruz Biotechnology; Santa Cruz, CA). The blots were then washed and incubated with a secondary goat or mouse antibody raised against rabbit IgG conjugated to horseradish peroxidase (1:2,000 dilution) (Santa Cruz Biotechnology; Santa Cruz, CA, USA). The bands were visualized by exposing the blots to X-ray film after incubation with ECL substrate for $5 \mathrm{~min}$ (SuperSignal; Pierce Biotechnology; Rockford, IL, USA), as described previously. ${ }^{15,20,23}$

\section{Statistical analysis}

One-way analysis of variance (ANOVA) was employed to evaluate significant changes in all cell treatment conditions compared to controls, except for the MTT assays where two-way ANOVA was used. Specifically for the MTT assay comparisons, in order to reveal if the effect of the various factors used for cell treatment is stable for different concentrations or between different FBS levels, the treatment factors were used as the stable factor (group), while their concentrations or $\%$ FBS were the repeated factor (group X concentration or FBS interactions; SPSS v. 22 statistical package, SPSS Inc. Headquarters; Chicago, USA). Where significant $\mathrm{F}$ ratios were found for main effect or interactions $(p<0.05)$, the means were compared using Tukey's post-hoc test, while Bonferroni corrections for multiple comparisons were performed where appropriate. All data are presented as mean \pm standard deviation (SD). The level of significance was set at $p<0.05$.

\section{RESULTS}

\section{Characterization of $h E c$ and $m E$ activity in vitro}

Synthetic hEc stimulated the proliferation of human PC-3 cells when grown in culture media supplemented with 10\% FBS, as assessed by MTT (Figure 1: panel A) and trypan blue assays (Figure 1: panel C). However, hEc did not stimulate significantly the proliferation of PC-3 cells in culture media supplemented with $0.5 \%$ FBS (Figure 1: panel B and panel D). These data suggest that $\mathrm{hEc}$ is a progression but not a competence growth factor. In addition, analysis of DNA content confirmed the ability of hEc to stimulate DNA synthesis in PC-3 cells, acting as progression factor (Figure 2: panel B) but not as a competence growth factor (Figure 2: panel E).

However, synthetic hEc did not stimulate (stimulation 20\%-30\%) mouse $\mathrm{C} 2 \mathrm{C} 12$ myoblasts (Figure 3: panel A) and synthetic $\mathrm{mE}$ did not stimulate human PC-3 cells under any experimental conditions (Figure $1 \&$ Figure 2: panel $\mathrm{C}$ and panel F). Moreover, synthetic $\mathrm{mE}$ stimulated the growth of mouse $\mathrm{C} 2 \mathrm{C} 12$ myoblasts (Figure 3: panel A \& panel B). These data suggest that synthetic $\mathrm{hEc}$ and $\mathrm{mE}$ exert species specific actions in vitro.

The mature IGF-1 acted both as a competence and a progression factor in our bioassay systems, while the scrambled peptide did not stimulate PC-3 cells and mouse $\mathrm{C} 2 \mathrm{C} 12$ myoblasts under any experimental conditions (Figure 1; Figure 2 and Figure 3). Inter- 
A.

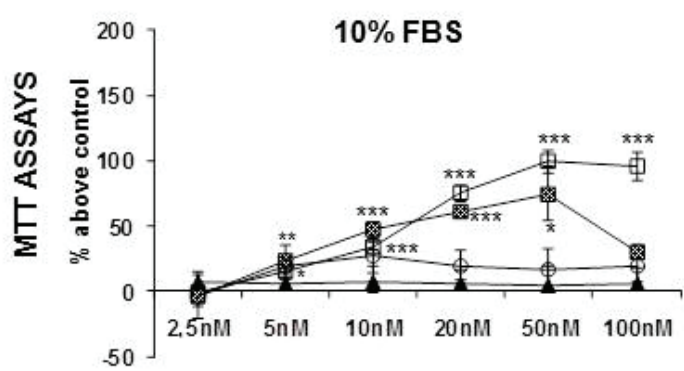

C.

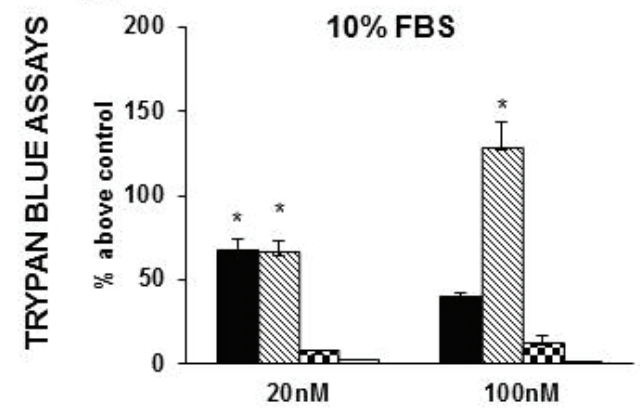

B.

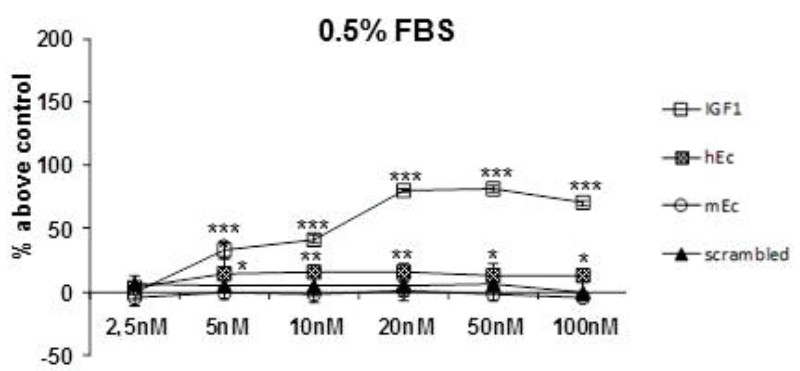

D.

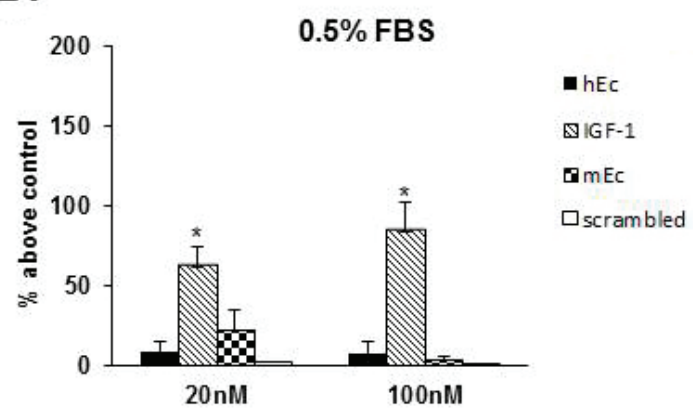

Figure 1. Proliferation assays on human PC-3 cells. The effects of synthetic peptides on metabolic activity proliferation and on the actual cell number of human PC-3 prostate cancer cells in vitro. The growth of human PC-3 cells was analyzed after 48hrs exposure to putative growth substances using various concentrations (dose-dependent effect). The rate of proliferation/metabolism of the human PC-3 cells was assessed by MTT assays (A) using cell culture media supplemented with 10\% fetal bovine serum (FBS). hEc resulted in a dose-dependent stimulation of cell proliferation/metabolism at concentrations of $2.5 \mathrm{nM}$ up to $50 \mathrm{nM}$, whereas hEc concentration $>100 \mathrm{nM}$ produced an over-dosing effect (A). $\mathrm{hEc}$ had no significant effect on human PC-3 cultures supplemented with $0.5 \%$ FBS (B). Unlike hEc, IGF-1 stimulated the growth of human PC-3 cells in both experimental conditions tested (0.5\% and 10\% FBS) (A, B). In addition, $\mathrm{mE}$ and scrambled peptide did not stimulate the growth of human PC-3 cells (A, B). Moreover, the trypan blue exclusion assays revealed similar results under identical experimental conditions (C, D). Mature IGF-1 produced significant increases in the actual number of PC-3 cells grown in both culture conditions $(0.5 \%$ and $10 \%$ FBS $)(C, D)$. Scrambled peptide did not stimulate the growth of $\mathrm{PC}-3$ cells in any experimental condition $(C, D)$. The results are expressed as means $\pm \mathrm{SD}(\mathrm{X} \pm \mathrm{SD})$ of three independent experiments performed in triplicate. $*$ : $\mathrm{p}<0.05, * *: \mathrm{p}<0.01, * * *: \mathrm{p}<0.001$ significantly different as compared to controls.

estingly, synthetic hEc exerted its actions within a relatively narrow range of concentrations $(5-50 \mathrm{nM})$, thus producing a significant over dosing effect at $100 \mathrm{nM}$. This effect was not noted by mature IGF-1 in vitro (Figure 1: panel $\mathrm{A}$ and panel $\mathrm{C}$ and Figure 2: panel A and panel D). A similar pattern of activity was documented also with $\mathrm{mE}$ in mouse $\mathrm{C} 2 \mathrm{C} 12$ myoblasts (Figure 3: panel A and panel B).

Analysis of the cell cycle revealed that the distribution of PC-3 cells at G1/G0 phase was increased in cultures supplemented with $0.5 \%$ FBS as compared to those supplemented with 10\% FBS (Figure 4: panel A vs panel D). The exogenous administration of $20 \mathrm{nM} \mathrm{hEc}$ or $20 \mathrm{nM}$ IGF-1 increased the distribution of $\mathrm{PC}-3$ cells into $\mathrm{S}$ phase at the expense of $\mathrm{G} 1 / \mathrm{G} 0$ phase (Figure 4: panel B and panel C, respectively). This data corroborates our results obtained by MTT, trypan blue exclusion and DNA content assays.

\section{Mode of hEc actions}

Investigating whether hEc activity in PC-3 cells is mediated by IGF-1R, we analyzed its effects in presence and absence of neutralizing anti-IGF-1R antibody and specific anti-human IGF1Ec antibody. ${ }^{22}$ Such analysis revealed that hEc's activity can be blocked by the anti-IGF1Ec antibody but not by the anti-IGF-1R antibody. The IGF-1 was used as a positive control for IGF-1R-mediated specific action (Figure 5: panel A; trypan blue assays and Figure 5: panel B; DNA content assays). 
A.

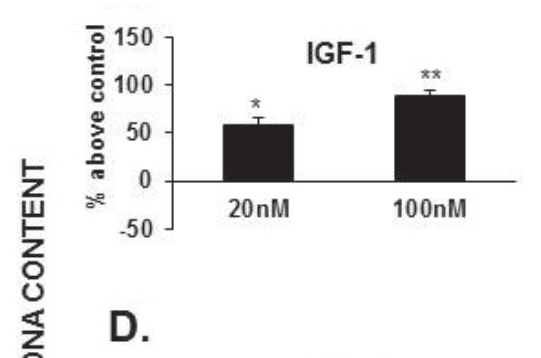

IGF-1

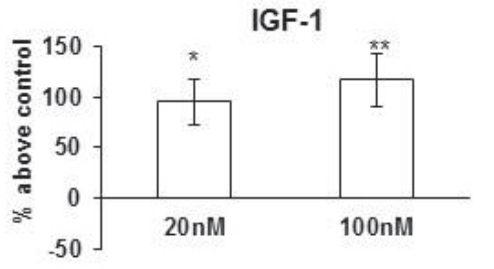

B.

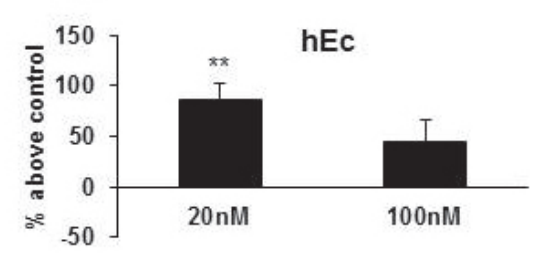

E.

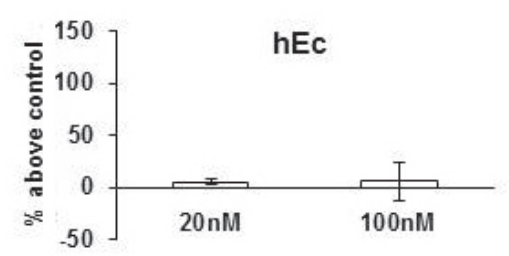

C.
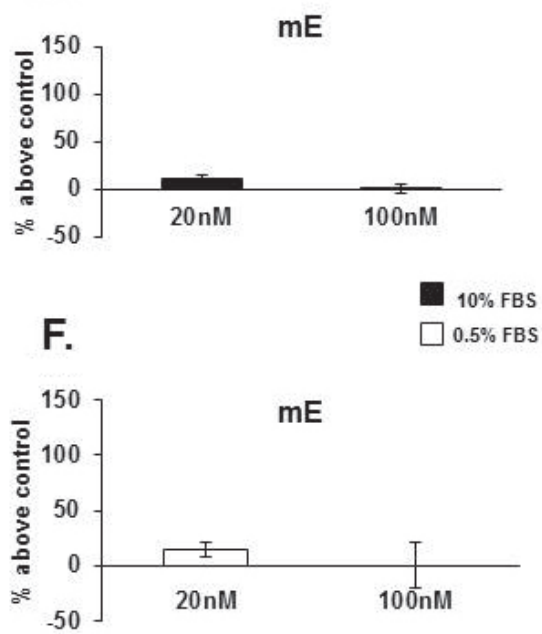

Figure 2. DNA content. The effects of the synthetic peptides were tested either in PC-3 cells grown in cell culture media supplemented with $10 \%$ or in media containing $0.5 \%$ FBS at concentrations of $20 \mathrm{nM}$ and $100 \mathrm{nM}$ for $48 \mathrm{hrs}$. The $20 \mathrm{nM}$ of the hEc peptide increased significantly the DNA content of PC-3 cells grown with 10\% FBS, while hEc at a concentration of 100nM produced an over-dosing effect (B). In addition, $\mathrm{mE}$ concentration of $20 \mathrm{nM}$ and $100 \mathrm{nM}$ did not increase the DNA content of human PC-3 cells (C, F). IGF-1 increased the DNA content in PC-3 cells grown under both experimental conditions $(0.5 \%$ and $10 \%$ FBS $)(A, D)$. The results are expressed as means $\pm \mathrm{SD}(\mathrm{X} \pm \mathrm{SD})$ of three independent experiments performed in triplicate. ${ }^{*}: \mathrm{p}<0.05,{ }^{* *}: \mathrm{p}<0.01,{ }^{* * *}: \mathrm{p}<0.001$ significantly different as compared to controls.

A.

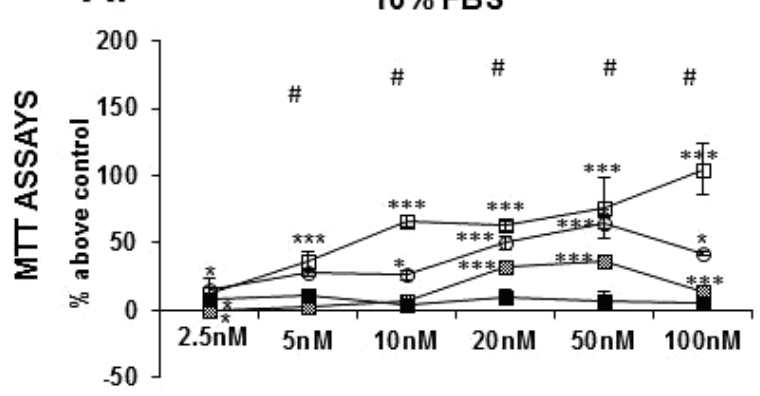

B.

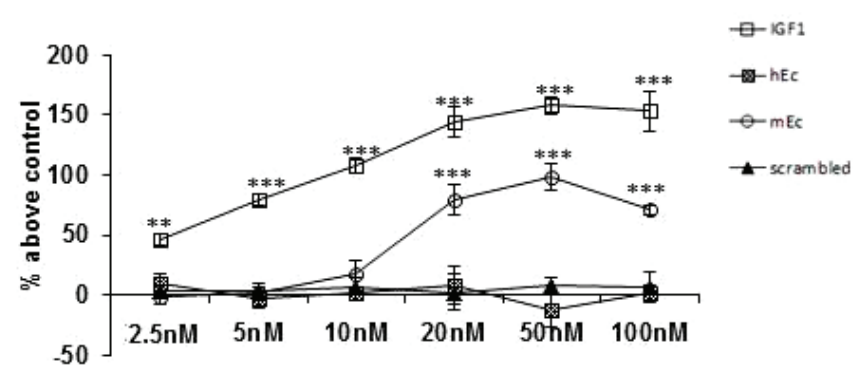

Figure 3. Proliferation assays for mouse $\mathrm{C} 2 \mathrm{C} 12$ cells. The ability of synthetic peptides to stimulate the proliferation of mouse $\mathrm{C} 2 \mathrm{C} 12$ myoblasts was assessed in PC-3 cells grown in cell culture media supplemented with 10\% FBS (A) and 0.5\% FBS (B). IGF-1 and mouse $\mathrm{mE}$ stimulated the growth of $\mathrm{C} 2 \mathrm{C} 12$ myoblasts in both experimental conditions. $\mathrm{hEc}$ and scrambled peptide did not stimulate the growth of $\mathrm{C} 2 \mathrm{C} 12$ myoblasts $(\mathrm{A}, \mathrm{B})$. The results are expressed as means $\pm \mathrm{SD}(\mathrm{X} \pm \mathrm{SD})$ of three independent experiments performed in triplicate. ${ }^{*}: \mathrm{p}<0.05, * *: \mathrm{p}<0.01,{ }^{* *}: \mathrm{p}<0.001$ significantly different as compared to controls, ${ }^{*}$ statistically significant compared to hEc peptide.

In addition, analysis of ERK1/2 and AKT phosphorylation by Western blots has revealed that $\mathrm{hEc}$ can activate ERK1/2 without affecting AKT (Figure 5: panel D). Again, mature IGF-1 was the positive control, knowing that it activates both ERK1/2 and AKT (Figure 5: panel C). The scrambled peptide activated neither ERK1/2 nor AKT in PC-3 cells after 5, 15, and $30 \mathrm{~min}$ (Figure 5: panel E). These data suggested that
hEc activates ERK1/2 via a mechanism that cannot be blocked by neutralizing IGF-1R antibody.

Furthermore, testing of synthetic hEc fragments enabled us to document that the $\mathrm{N}$-terminal fragment of hEc [hEc (1-12)] is inactive. However, similarly to full length $\mathrm{hEc}$, all the C-terminal fragments of $\mathrm{hEc}$ were active in PC-3 cells grown in culture media 
A.
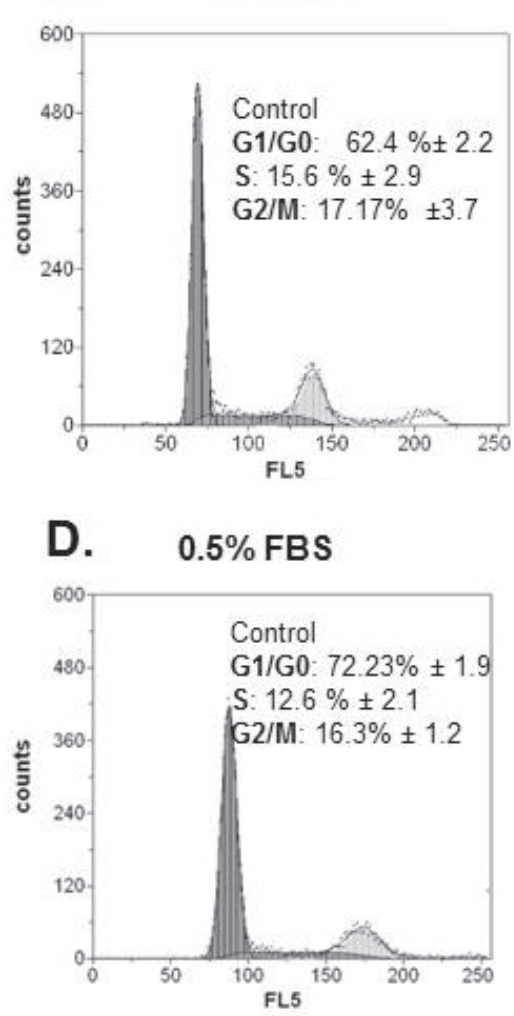

B.

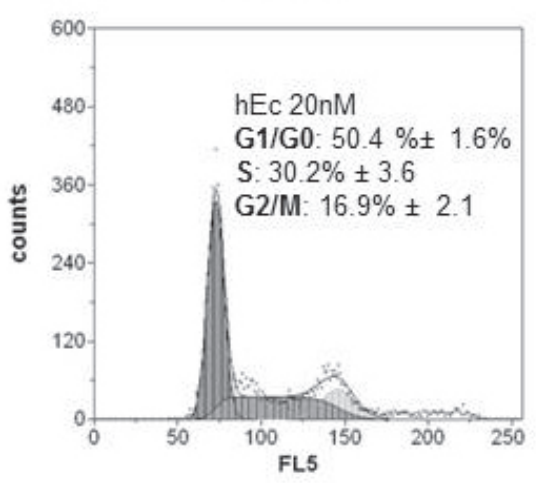

E.

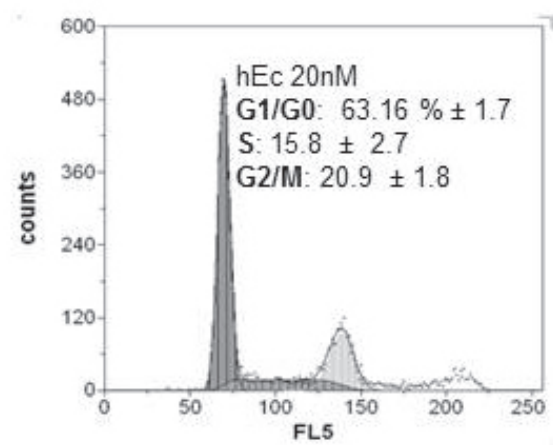

C. $10 \% \mathrm{FBS}$

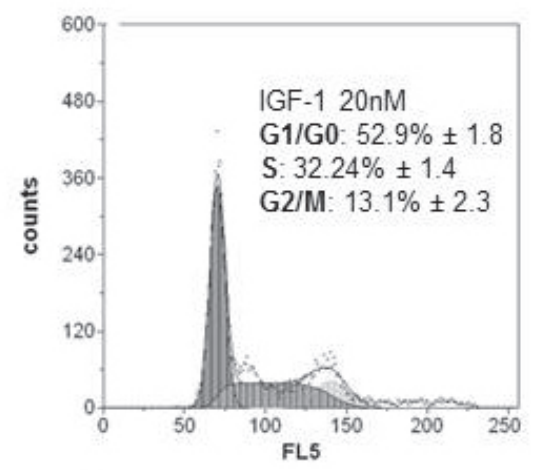

F.

\section{$0.5 \%$ FBS}

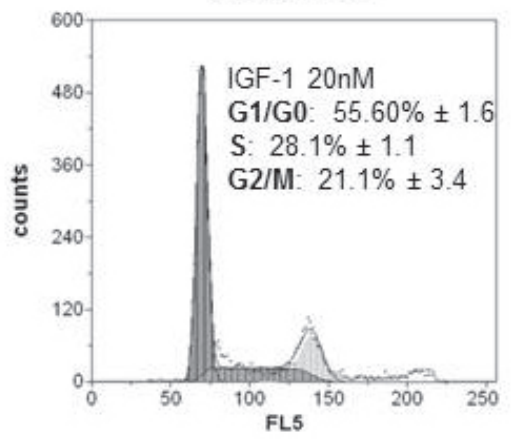

Figure 4. Cell cycle analysis. Analysis of phase distribution of human PC-3 cells grown in cell culture media supplemented with $10 \%$ FBS and $0.5 \%$ fetal bovine serum (FBS), after stimulation with the synthetic peptides under investigation, as assessed by flow cytometry. The human PC-3 cells, which were grown with culture media containing $0.5 \%$ FBS, had an increased cell distribution in the G1/ G0 phase as compared to PC-3 cells grown with 10\% FBS (A, D). In addition, stimulation with hEc and IGF-1 increased the distribution of PC-3 cells in the S phase at the expense of the G1/G0 phase (A, B). This hEc effect was not evident in PC-3 cells grown with culture media containing $0.5 \%$ FBS $(\mathrm{B}, \mathrm{E})$.

supplemented with $10 \%$ FBS [hEc (13-24) and hEc (21-24)] (Figure 6: panel A; trypan blue assays and Figure 6: panel B; DNA content assay). The analysis of ERK1/2 and AKT phosphorylation revealed that all the hEc fragments containing the last $4 \mathrm{aa}$ of its C-terminal end provoked the activation of ERK1/2 without affecting AKT [hEc (13-24 and hEc (21-24)] and acted as progression factors in human PC-3 cells. The N-terminal hEc [hEc (1-12)] did not affect ERK1/2 activation and growth of PC-3 cells (Figure 6: panel $\mathrm{C}$, panel D and panel E). Therefore, we concluded that the active core of $\mathrm{hEc}$ is located in the last $4 \mathrm{aa}$ of its C-terminal end.

\section{DISCUSSION}

The time frame between two mitotic divisions is known as the somatic "cell cycle", while "interphase" is the time from the end of one mitosis, or mitotic (M) phase, until the start of the next one. After completion of mitosis, cells may either enter a condition called G1 phase, during which RNAs and proteins are synthesized but there is no DNA replication, or withdraw from the cell cycle into the G0 phase (quiescence/dormancy). G0 phase cells can reenter the cell cycle ( $\mathrm{G} 0$ to $\mathrm{G} 1$ transition) with the action of competence growth factors, such as platelet-derived growth factor (PDGF) and basic fibroblast growth factor (bFGF). ${ }^{25-27}$ Competence growth factors can initiate this process via the activation of transcription factors which are the products of the so-called "early response genes" (proto-oncogenes), such as c-fos and c-myc and ras. The gatekeeper p53, among other events, controls the G0 to G1 transition. ${ }^{28,29}$ In 
A.

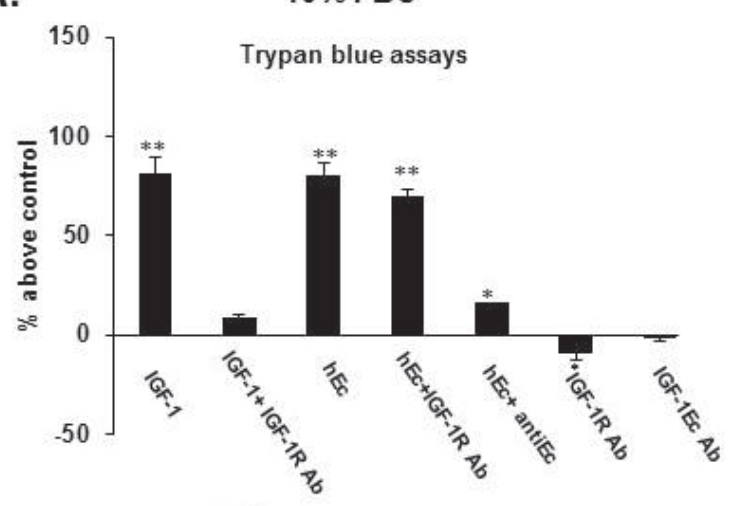

B.

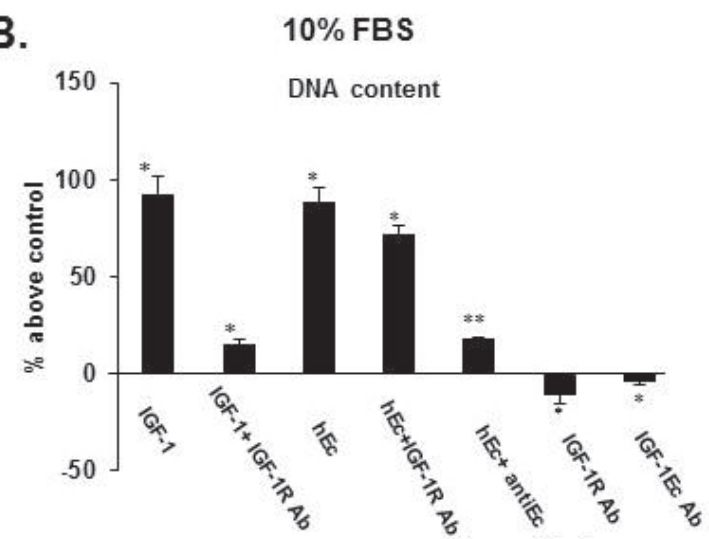

c.
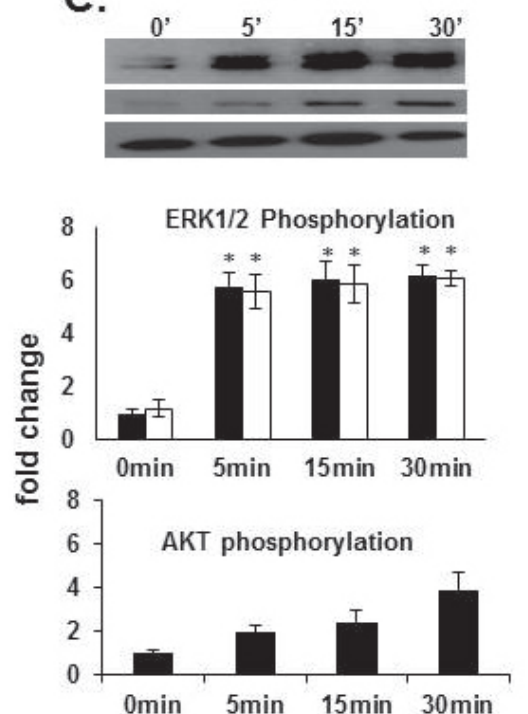

D.
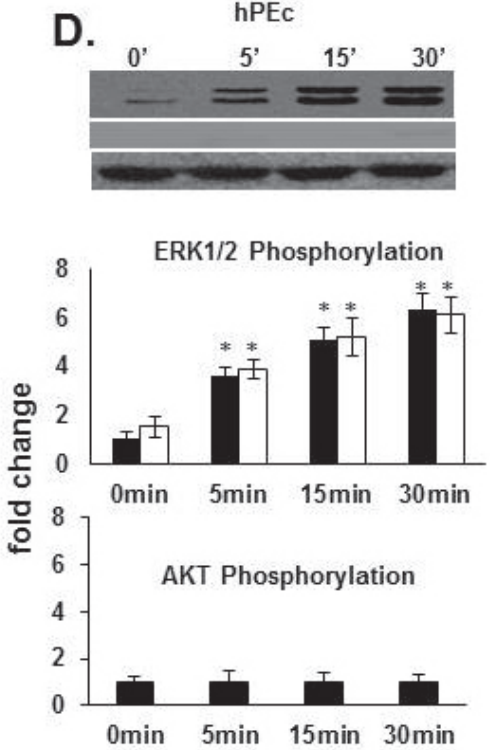

E.

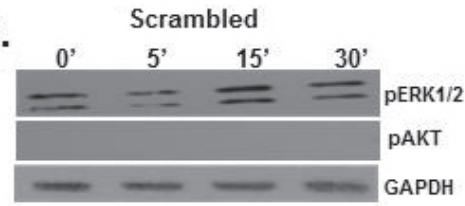

Figure 5. Mitogenic effects of the putative growth substances. Analysis of the mitogenic effects of putative growth substances tested on human PC-3 cells, using cell culture pre-incubated with neutralizing IGF-1R antibody or IGF-1Ec antibody. The analysis involved trypan blue exclusion assays (A) and DNA content assays (B). Pre-incubation with anti-IGF-1R Ab blocked the effect of IGF-1 but it did not alter the proliferative effects of hEc on human PC-3 cells. However, the anti-IGF-1Ec antibody neutralized the proliferative effects of hEc on human PC-3 cells. Furthermore, Western blot analysis revealed that IGF-1 activated both ERK1/2 and AKT in PC-3 cells (C). However, synthetic hEc activated ERK1/2 but not AKT (D). The scrambled peptide did not activate ERK1/2 and AKT in PC-3 cells (E). The results are expressed as means $\pm \mathrm{SD}(\mathrm{X} \pm \mathrm{SD})$ of three independent experiments performed in triplicate. *: $\mathrm{p}<0.05$, $* *$ : $\mathrm{p}<0.01, * * *: \mathrm{p}<0.001$ significantly different as compared to controls.

vitro, the supplementation of cell culture media with significant amounts of serum $(>5 \%)$ provides the cells with competence and progression factors necessary to maintain cell survival and growth in vitro. Serum deprivation $(0.5 \% \mathrm{FBS})$ is an experimental technique aiming to synchronize somatic cells in the G0 phase in vitro. It is well known that cancer cells and cell lines require less serum supplementation to achieve efficient survival and growth in vitro. ${ }^{25-29}$
In the late $\mathrm{G} 1$ phase the cells reach the restriction point (R); beyond this point cells are committed to DNA replication in the $\mathrm{S}$ (synthesis) phase. Other growth factors, such as epidermal growth factor (EGF) and IGF-1, are progression growth factors, accelerating the transition of cells already in the cell cycle from the G1 to G2 phase. Notably, the progression from $\mathrm{G} 2$ phase to $\mathrm{M}$ phase is independent of further growth factor stimulation. ${ }^{29}$ The above is crucial background 


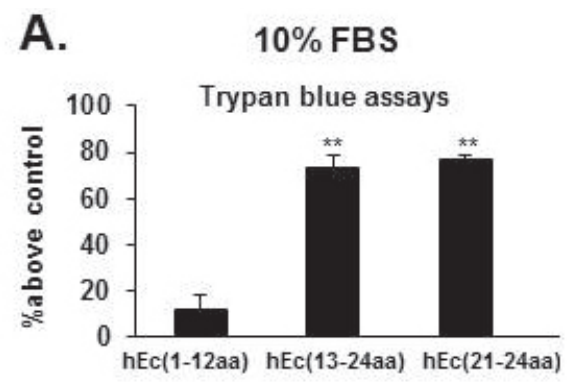

B.

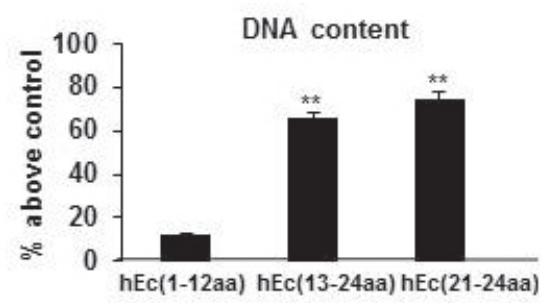

C.
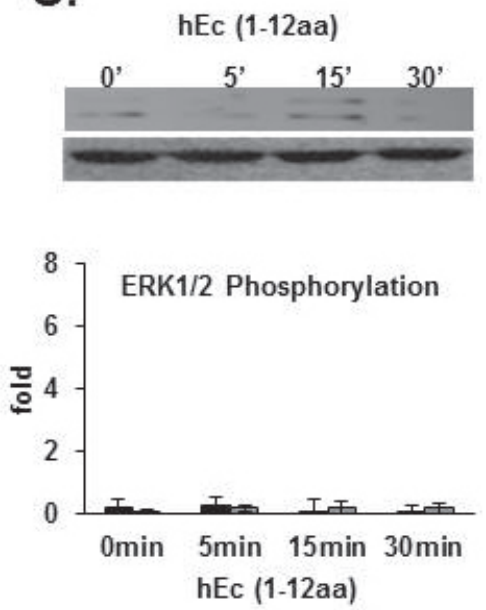

D.
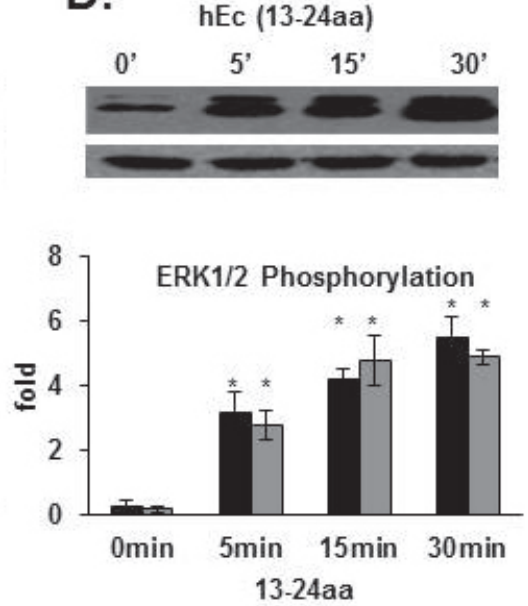

E.
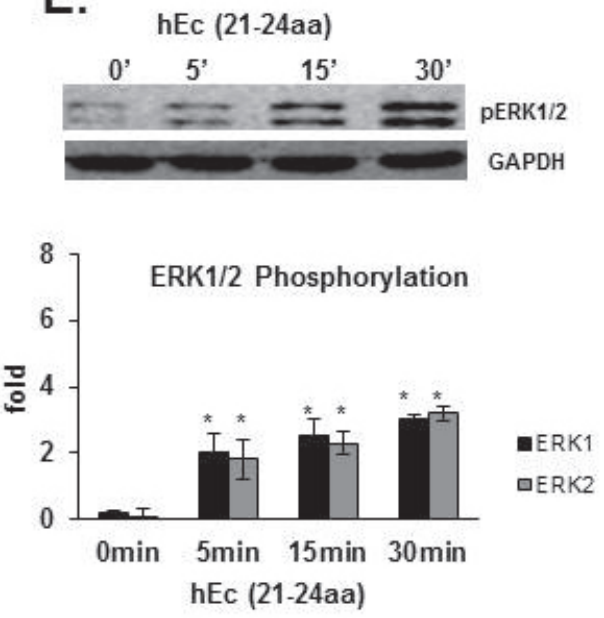

Figure 6. Mitogenic effects of the synthetic fragments of hEc. The synthetic fragments of $h E c$ (a) $h E c(1-12)$, (b) $h E c$ (13-24), (c) hEc (21-24) were tested for mitogenic activity in human PC-3 cells using trypan blue exclusion assays (A) and DNA content assays (B). The fragment hEc (1-12) did not affect the growth of human PC-3 cells (A, B). However, all the synthetic fragments that contained the last 4 amino acids (aa) of the hEC's C-terminal end stimulated the growth of human PC-3 cells. In addition, the synthetic fragments, hEc (13-24) and hEc (21-24), activated ERK1/2 (D, E), while the synthetic hEc (1-12) did not affect the phosphorylation of ERK1/2 in human PC-3 cells (C).

knowledge in cell physiology that enables analysis of the role of putative growth substances in vitro. Therefore, when testing for putative mitogens in cell cultures using culture media supplemented with $0 \%-0.5 \%$ FBS (cells trapped in the G0 phase), the process is not expected to detect any bioactivity if the substance under investigation is only a progression factor without competence growth factor activity. ${ }^{21}$ According to our results this is the case of hEc in vitro.

Moreover, our data revealed that $\mathrm{hEc}$ possesses species-specific activity, acting as a progression factor in human PC-3 cells but not in mouse $\mathrm{C} 2 \mathrm{C} 12$ myoblasts. hEc did not stimulate significantly $(20 \%-30 \%$; $\mathrm{p}>0.05)$ the growth of $\mathrm{C} 2 \mathrm{C} 12$ myoblasts. All the synthetic $\mathrm{hEc}$ fragments that contained the last $4 \mathrm{aa}$ of the $\mathrm{hEc} \mathrm{C}$-terminal end exerted this species-specific activity. The synthetic hEc fragment that contained the $\mathrm{N}$-terminal end was documented as being inactive in all bioassay systems. Similarly, $\mathrm{mE}$, which was active in mouse $\mathrm{C} 2 \mathrm{C} 12$ myoblasts, did not stimulate significantly the growth of human PC-3 cells. Since the last 4 amino acids of the C-terminal end of $\mathrm{hE}$ and $\mathrm{mE}$ differ only in the amino acid residue at position 23, the role of rat position 23 in $\mathrm{hEc}$ appears crucial for its biological action on human PC-3 cells. Interestingly, in the literature the first synthetic $\mathrm{hEc}$ peptide was initially produced bearing an unexplained modification of its sequence at residue 23 (H instead of R), apparently copying the aa sequence of the $\mathrm{mE}$ C-terminal end. ${ }^{31,32}$ Conceivably, such a change, which was repeated thereafter by other investigators, has contributed to the confusing data about hEc's activity using either human or mouse in vitro systems. 
Furthermore, synthetic $\mathrm{hEc}$ exerted its action within a very narrow concentration range, reaching a plateau of its dose-dependent effects at 50nM (optimal dose for in vitro testing $=20 \mathrm{nM}$ ). The testing of $\mathrm{hEc}$ action at a concentration of $100 \mathrm{nM}$ produced no significant stimulation of the growth of human PC-3 cells in vitro. Therefore, it is conceivable that the contradicting reports on hEc's actions may be attributable to the variability of experimental settings (human and mouse models), the narrow range of activity (tests performed at $100 \mathrm{nM}$ ) and the absence of competence factor activity (testing in media with $0 \% \mathrm{FBS}$ ).

$\mathrm{hEc}$ action was not blocked by neutralizing the anti-IGF-1R antibody, while its effect was blocked by the anti-human IGF-1Ec antibody. These data corroborate previous reports on $\mathrm{hEc}$ action ${ }^{15,16}$ and the recently reported oncogenic role of hEc in PC-3 prostate cancer cells and immortalized (SV-40) human prostate cancer epithelial cells (HPrEC cells), both molecularly engineered to overexpress specifically hEC (PC-3hEc and HPrEc-hEc transfectans), in vitro and in vivo. ${ }^{20}$ Interestingly, HPrECP-hEc cells, orthotopically injected into SCID mice, provoked metastases in these mice. Immortalized HPrEC cells without expression of Ec do not produce metastases; however, all the SCID mice injected with HPrECP$\mathrm{hEc}$ cells died within 12 weeks, showing a remarkable increase in the mortality rate. ${ }^{20}$ Furthermore, hEc overexpression produced epithelial to mesenchymal transition (EMT) in PC-3hEc cells and PC-3hEcinduced tumours in SCID mice. Notably, hEc-induced EMT was causatively mediated by ERK $1 / 2$ activation and ZEB-1 expression, however, by a mechanism that was independent of IGF-1R signalling. ${ }^{20}$

In addition, we recorded strong evidence supporting the notion that IGF-1Ec overexpression in prostate cancer tumours (PC-3hEc tumours in SCID mice) is provoked by the host's immune reaction. Indeed, PC-3hEc cells are able to attract and to increase the invasiveness of human mesenchymal cells in vitro, while IGF-1Ec expression is enhanced in PC-3 cells after co-culturing with pre-sensitized human mesenchymal cells. ${ }^{20}$ In cancer biology, bone marrow-derived mesenchymal stem cells (MSCs) are locally recruited to establish a supportive stroma around the tumour, a phenomenon elicited by the release of paracrine signals by the tumour. Bearing in mind the above, our data suggesting an overexpression of IGF-1Ec by injured tissues, such as by the surrounding tissues in prostate cancer, is reminiscent of the preferential expression of IGF-1Ec post-skeletal muscle damage and that of the myocardium during the post-infarction period..$^{30-36}$

Interestingly, species-specific differences of $\mathrm{hEc}$ and $\mathrm{mE}$ actions may point to a possible different mode of actions at the receptor level. It has been reported that $\mathrm{mE}$ requires IGF-1R for its bioactivity, ${ }^{36}$ while $\mathrm{hEc}$ appears to act in an IGF-1R independent manner. ${ }^{15,20,33}$ Thus, the residue rat position $23 \mathrm{of} \mathrm{hEc}$ is probably crucial for $\mathrm{hEc}$ receptor recognition.

Taking into consideration all these data, we conclude that $\mathrm{hEc}$ is a progression factor for human PC-3 cells but not for mouse $\mathrm{C} 2 \mathrm{C} 12$ myoblasts, that it increases the growth and metastatic capability of PC-3 hEc and HPrECP-hEc transfectans in vitro and in vivo and that $\mathrm{hEc}$ overexpression can induce EMT of PC-3 cells via an IGF-1R-independent [possibly via a $h E c$ receptor (hEc.R)].

\section{CONCLUSION}

hEc may have an important role in human prostate cancer biology. Since the preferential overexpression of IGF-1Ec in several pathologies produces both IGF-1 and $\mathrm{hEc}$, it is conceivable that the biological role of $\mathrm{hEc}$ may be auxiliary to that of IGF-1 (additive and/ or synergistic/antagonistic actions) in human tissues which undergo repair/remodeling and/or in the tumour microenvironment (host-tumour cell interactions). We therefore conclude that further investigation into the possible biological role of $\mathrm{E}$ domain products of igfl is warranted.

\section{DISCLOSURE}

The authors declare they have no competing interests that might be perceived to influence the results and discussion reported in this paper.

\section{REFERENCES}

1. Baker J, Hardy MP, Zhou J, 1996 Effects of an Igf1 gene null mutation on mouse reproduction. Mol Endocrinol 10: 903-918.

2. Philippou A, Halapas A, Maridaki M, Koutsilieris M, 2007 Type I insulin-like growth factor receptor signal- 
ing in skeletal muscle regeneration and hypertrophy. $\mathrm{J}$ Musculoskelet Neuronal Interact 7: 208-218.

3. Philippou A, Maridaki M, Pneumaticos S, Koutsilieris M, 2014 The complexity of the IGF1 gene splicing, posttranslational modification and bioactivity. Mol Med 20: 202-214.

4. Ma QL, Yang TL, Yin JY, et al, 2009 Role of insulinlike growth factor-1 (IGF-1) in regulating cell cycle progression. Biochem Biophys Res Commun 389: 150-155.

5. Mairet-Coello G, Tury A, DiCicco-Bloom E, 2009 Insulin-like growth factor-1 promotes $\mathrm{G}(1) / \mathrm{S}$ cell cycle progression through bidirectional regulation of cyclins and cyclin-dependent kinase inhibitors via the phosphatidylinositol 3-kinase/Akt pathway in developing rat cerebral cortex. J Neurosci 29: 775-788.

6. Armakolas A, Philippou A, Panteleakou Z, et al, 2010 Preferential expression of IGF-1Ec (MGF) transcript in cancerous tissues of human prostate: evidence for a novel and autonomous growth factor activity of MGF E peptide in human prostate cancer cells. Prostate 70: 1233-1242.

7. Siegfried JM, Kasprzyk PG, Treston AM, Mulshine JL, Quinn KA, Cuttitta F, 1992 A mitogenic peptide amide encoded within the $\mathrm{E}$ peptide domain of the insulin-like growth factor IB prohormone. Proc Natl Acad Sci U S A 89: 8107-8111.

8. Gilmour RS, 1994 The implications of insulin-like growth factor mRNA heterogeneity. J Endocrinol 140: $1-3$.

9. Kuo YH, Chen TT, 2002 Novel activities of pro-IGF-I E peptides: regulation of morphological differentiation and anchorage-independent growth in human neuroblastoma cells. Exp Cell Res 280: 75-89.

10. Philippou A, Armakolas A, Panteleakou Z, 2011 IGF1Ec expression in MG-63 human osteoblast-like osteosarcoma cells. Anticancer Res 31: 4259-4265.

11. Mills P, Dominique JC, Lafreniere JF, Bouchentouf M, Tremblay JP, 2007 A synthetic mechano growth factor E Peptide enhances myogenic precursor cell transplantation success. American journal of transplantation. Am J Transplant 7: 2247-2259.

12. Collins JM, Goldspink PH, Russell B, 2010 Migration and proliferation of human mesenchymal stem cells is stimulated by different regions of the mechano-growth factor prohormone. J Mol Cell Cardiol 49: 1042-1045.

13. Deng M, Zhang B, Wang K, 2011 Mechano growth factor E peptide promotes osteoblasts proliferation and bone-defect healing in rabbits. Int Orthop 35: 10991106.

14. Mills P, Lafreniere JF, Benabdallah BF, El Fahime el M, Tremblay JP, 2007 A new pro-migratory activity on human myogenic precursor cells for a synthetic peptide within the E domain of the mechano growth factor. Exp Cell Res 313: 527-537.

15. Philippou A, Papageorgiou E, Bogdanis G, 2009 Expres- sion of IGF-1 isoforms after exercise-induced muscle damage in humans: characterization of the MGF E peptide actions in vitro. In vivo 23: 567-575.

16. Milingos DS, Philippou A, Armakolas A, et al, 2011 Insulinlike growth factor-1Ec (MGF) expression in eutopic and ectopic endometrium: characterization of the MGF E-peptide actions in vitro. Mol Med 17: 21-28.

17. Chew SL, Lavender P, Clark AJ, Ross RJ, 1995 An alternatively spliced human insulin-like growth factor-I transcript with hepatic tissue expression that diverts away from the mitogenic IBE1 peptide. Endocrinology 136: 1939-1944.

18. Philippou A, Armakolas A, Koutsilieris M, 2013 Evidence for the Possible Biological Significance of the igf-1 Gene Alternative Splicing in Prostate Cancer. Front Endocrinol (Lausanne) 4: 31.

19. Savvani A, Petraki C, Msaouel P, Diamanti E, Xoxakos I, Koutsilieris M, 2013 IGF-IEc expression is associated with advanced clinical and pathological stage of prostate cancer. Anticancer Res 33: 2441-2445.

20. Armakolas A, Kaparelou M, Dimakakos A, 2015 Oncogenic Role of the Ec Peptide of the IGF-1Ec Isoform in Prostate Cancer. Mol Med 21: 167-179.

21. Fornaro M, Hinken AC, Needle S, et al, 2014 Mechanogrowth factor peptide, the $\mathrm{COOH}$ terminus of unprocessed insulin-like growth factor 1, has no apparent effect on myoblasts or primary muscle stem cells. Am J Physiol Endocrinol Metab 306: E150-156.

22. Philippou A, Stavropoulou A, Sourla A, et al, 2008 Characterization of a rabbit antihuman mechano growth factor (MGF) polyclonal antibody against the last 24 amino acids of the E domain. In vivo 22: 27-35.

23. Papageorgiou E, Pitulis N, Manoussakis M, Lembessis P, Koutsilieris M, 2008 Rosiglitazone attenuates insulin-like growth factor 1 receptor survival signaling in PC-3 cells. Mol Med 14: 403-411.

24. Koutsilieris M, Mastrogamvrakis G, Lembessis P, Sourla A, Miligos S, Michalas S, 2001 Increased insulin-like growth factor 1 activity can rescue KLE endometriallike cells from apoptosis. Mol Med 7: 20-26.

25. Stiles CD, Capone GT, Scher CD, Antoniades HN, Van Wyk JJ, Pledger WJ, 1979 Dual control of cell growth by somatomedins and platelet-derived growth factor. Proc Natl Acad Sci U S A 76: 1279-1283.

26. Lin VK, Ortwerth BJ, 1983 Competence and progression growth factors stimulate different tRNAlys modification reactions in BALB/C 3 T3 cells. Biochem Biophys Res Commun 115: 598-605.

27. Stiles CD, 1985 The biological role of oncogenes-insights from platelet-derived growth factor: Rhoads Memorial Award lecture. Cancer Res 45: 5215-5218.

28. Braun-Dullaeus RC, Mann MJ, Dzau VJ, 1998 Cell cycle progression: new therapeutic target for vascular proliferative disease. Circulation 98: 82-89.

29. Gerard C, Goldbeter A, 2015 Dynamics of the mam- 
malian cell cycle in physiological and pathological conditions. Wiley Interdiscip Rev Syst Biol Med 8: 140-156.

30. McKoy G, Ashley W, Mander J, 1999 Expression of insulin growth factor-1 splice variants and structural genes in rabbit skeletal muscle induced by stretch and stimulation. J Physiol 516: 583-592.

31. Hameed M, Lange KH, Andersen JL, et al, 2004 The effect of recombinant human growth hormone and resistance training on IGF-I mRNA expression in the muscles of elderly men. J Physiol 555: 231-240.

32. Goldspink G, 2004 Age-related loss of skeletal muscle function; impairment of gene expression. J Musculoskelet Neuronal Interact 4: 143-147.
33. Pena JR, Pinney JR, Ayala P, Desai TA, Goldspink PH, 2015 Localized delivery of mechano-growth factor E-domain peptide via polymeric microstructures improves cardiac function following myocardial infarction. Biomaterials 46: 26-34.

34. Philippou A, Barton ER, 2014 Optimizing IGF-I for skeletal muscle therapeutics. Growth Horm IGF Res 24: 157-163.

35. Bikle DD, Tahimic C, Chang W, Wang Y, Philippou A, Barton ER, 2015 Role of IGF-I signaling in muscle bone interactions. Bone 80: 79-88.

36. Brisson BK, Barton ER, 2013 New Modulators for IGF-I Activity within IGF-I Processing Products. Front Endocrinol (Lausanne) 4: 42. 